\title{
Isoamyl 2-cyanoacrylate interposition in the urethro-cutaneous fistula repair: A randomized controlled trial
}

\author{
A. M. Tawfeek (1D, Andrew Makeen Mohareb, Ahmed Higazy* ${ }^{*}$, Ahmed Farouk, Karim Omar Elsaeed, \\ Ahmed Tawfick and Ahmed Radwan
}

\begin{abstract}
Background: We aim to evaluate isoamyl 2-cyanoacrylate as an intervening layer in the surgical repair of the urethracutaneous fistula (UCF) after hypospadias in comparison with the classic surgical repair technique.

Methods: Between January 2017 and July 2018, 40 patients with UCF were randomized into two equal groups. Group I represented a multilayered closure with dartos fascia flap while using cyanoacrylate glue as an interposition layer, while group II represented the same procedure without applying the glue. We followed up our patients for 6 months following the procedure to evaluate a successful closure.

Results: Forty patients were available for evaluation at the end of our study. There was no statistically significant difference between the two groups regarding their demographic data. The mean fistula size was $3.25 \pm 0.64$ and $3.15 \pm 0.75 \mathrm{~mm}$ in group I and II, respectively, with a statistically significant difference. Successful UCF closure was achieved in $80 \%$ of cases in group I (16/20) and 70\% of group II (14/20) with no statistically significant difference. There was no statistically significant difference between both groups as regards the occurrence of mild complications in the postoperative period, which was $10 \%$ in both groups.

Conclusion: The application of cyanoacrylate during UCF repair was feasible and safe. The successful repair of UCF was found to be higher with cyanoacrylate. However, we could not demonstrate a statistically significant difference between the two groups.

Trial registration number The trial is registered at clinicaltrial.gov with trial registration number: NCT04876976 (retrospective registration)
\end{abstract}

Keywords: Isoamyl 2-cyanoacrylate, Urethra-cutaneous fistula, Hypospadias, Fistula repair

\section{Background}

Hypospadias is a common congenital urological anomaly with a ventrally located urethral meatus with a prevalence of 5-50 per 10,000 births [1]. Urethro-cutaneous fistula (UCF) remains by far the most common postoperative complication of hypospadias surgical repair, and

*Correspondence: Ahmedmaherhigazy@gmail.com; Ahmedmaher@med. asu.edu.eg

Ain Shams University, Cairo, Egypt it remains the primary concern of surgeons dealing with hypospadias repair $[2,3]$.

The incidence of UCF after hypospadias surgical repair varies from surgeon to surgeon; the average reported incidence of UCF is approximately $35 \%$. In a large study by Barbagli et al., the incidence of complications in the hypospadias repair was $64.6 \%$ and UCF represented the most common complication reported in this study with a percentage of 20.7 [4-6].

The technique of fistula repair is determined based on various factors including the size, location, number of 
fistulas, and the condition of the surrounding penile skin. Many techniques have been developed for UCF correction with variable outcomes. Classic multilayer repair is the most commonly used method for fistula repair, especially for small-sized fistulas. However, a high recurrence rate is still present [7-9].

Cyanoacrylate is a group of synthetic adhesives that form a strong adhesive with a variety of substrates on contact with water or other fluids. The non-toxic forms that are used in medicine are the isobutyl 2-cyanoacrylate, isoamyl 2-cyanoacrylate, and 2-octyl cyanoacrylate with their synonyms [10].

Cyanoacrylate products have both waterproof and bacteriostatic properties, which allows their wide use for surgical wound primary closure, and it has been used to some extent in suture-less circumcision and pediatric lacerations. They have been used for the repair of UCF in outpatient settings as their tensile strength maintains an adequate contact of the fistula's edges leading to enhanced healing [11-13].

In our study, we are investigating the added advantage of using isoamyl 2-cyanoacrylate as an interposition substance in surgical repair of UCF after hypospadias in comparison with the classic surgical repair technique.

\section{Methods}

Between January 2017 and July 2018, 40 patients with UCF after hypospadias surgical repair were enrolled in our study. Patients with UCF regardless of their age were included in our study. Patients with fistula size more than $5 \mathrm{~mm}$, multiple fistulas, uncorrected obstruction distal to the fistula, necrotic tissue, active infection at the fistula site, severely scarred skin, deficient dartos around the fistula, fistulas more proximal to the mid-penile position, recurrent fistulas, or previous history of hypersensitivity to cyanoacrylate-based products were excluded from our study.

After obtaining informed consent from the legal guardian, patients were randomized into two equal groups with a 1:1 ratio using sealed envelopes that were prepared by the department's ethical committee. The staff who performed the follow-up and data analysis were kept blinded to each patient's allocation. Cases of group (I) underwent multilayered closure using dartos facial flap and cyanoacrylate glue as an interposition layer. Cases of the control group (II) underwent the same procedure without using cyanoacrylate. All procedures were done by two expert surgeons.

\section{Preoperative considerations}

Each patient was carefully examined. Details of the previous repair were reviewed, including age at the time of operation, type of hypospadias, the technique of primary repair, and postoperative complications such as infection and penile edema.

A detailed description of the fistulas was recorded, including the time of presentation after the operation, number, site, and size of the fistula.

Urine analysis and culture were performed, and UTI was managed by using the appropriate antibiotics before surgery.

\section{Operative technique}

Calibration of the distal urethra was performed to ensure no distal obstruction is present that may require concomitant repair. The site and number of fistulas were identified by injecting normal saline with a syringe through the meatus after applying manual pressure proximally at the penoscrotal region to close the urethra. After urethral calibration and identification of the fistulas, an appropriate size silicone catheter was inserted.

In group I, the site of the fistula was marked with a skin marker, and a circumferential incision was made in the marked area and carried down to the dartos layer of the penis. The fistulous tract was dissected down to the healthy urethra. The edges were trimmed (de-epithelialized) and inverted using 6/0 Vicryl continuous suture and subsequently closed with an interrupted suture as the first layer of closure to ensure watertight closure. The repaired fistulas were tested for any leakage by injection of saline into the urethra with gentle proximal pressure on the urethra.

Two to three drops of cyanoacrylate were sprayed on the suture line as a second protective layer. An amount of $0.2-0.3 \mathrm{ml}$ was used per case over the suture line. Each ampoule of (Amcrylate ${ }^{\circledR}$, Concord Drugs Ltd., India) contains $0.5 \mathrm{ml}$ of isoamyl 2-cyanoacrylate. The cyanoacrylate glue was polymerized in seconds, and a hard, adherent layer was formed representing the second layer of repair. Any excess fragments of cyanoacrylate were removed. Afterward, the dartos fascia flap was applied over the suture line and closed as a third protective layer using 6/0 Vicryl interrupted sutures.

In group II, closure of urethra-cutaneous fistula with second layer covering using dartos flap was done. The same steps of the procedure were followed without using cyanoacrylate glue as an intermediate protective layer.

\section{Postoperative considerations}

Patients were discharged on the second day following the procedure. The catheter was removed on the 7 th day after the operation.

The evaluation was made weekly for one month and then monthly up to 6 months postoperative through appropriate history taking and clinical examination including inspection for the presence of postoperative 
complications such as penile edema or infection and inspection to the urine stream during voiding and the presence of a recurrent fistula.

Success was defined as no abnormal fistulation, satisfactory urine caliber, and force of the stream. Side effects such as infection, edema, and disfigurement were recorded for both techniques.

\section{Ethical approval}

The protocol was approved by the research ethics committee of our institute (Approval No. FMASU MS 75/2018).

\section{Statistical analysis}

Using Statistical Package for Social Science (IBM SPSS) version 23 , the quantitative data were demonstrated as mean, standard deviations, and ranges and the independent $\mathrm{t}$-test was used, while qualitative variables were presented as numbers and percentages and were compared using the Chi-square test. $P$-value $<0.05$ was considered statistically significant for all variables.

\section{Results}

Forty patients have been analyzed in our study as shown in Fig. 1. The mean age of our patients was 5.5 years (3-17) in group I and 5 years (3-16) in group II. In group I, the mean fistula size was $3.25 \mathrm{~mm} \pm 0.64$,

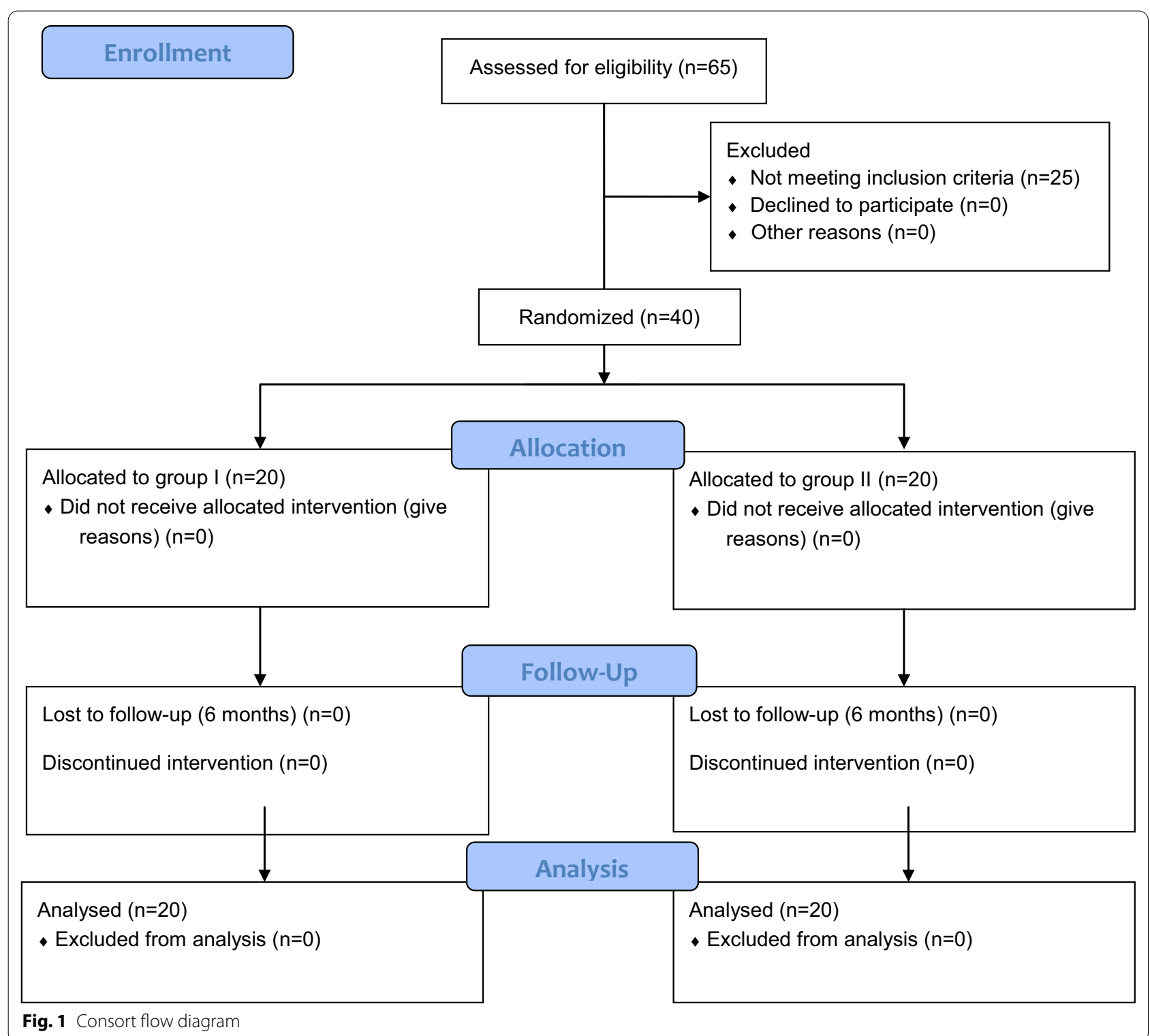


Table 1 General characteristics of the patients

\begin{tabular}{lllll}
\hline Characteristics & Group I, $\boldsymbol{N}=\mathbf{2 0}$ & Group II, $\mathbf{N}=\mathbf{2 0}$ & $\boldsymbol{P}$-value \\
\hline Age (years) (median) & & $5.5(3-17)$ & $5(3-16)$ & 0.81 \\
Fistula diameter (mm) & & $3.25 \pm 0.64$ & $3.15 \pm 0.75$ & 0.085 \\
Fistula site & Coronal & $1(5 \%)$ & $2(10 \%)$ & 0.45 \\
& Distal penile & $12(60 \%)$ & $13(65 \%)$ & 0.23 \\
& Mid-penile & $7(35 \%)$ & $5(25 \%)$ & 0.55 \\
\hline
\end{tabular}

Data presented as mean \pm standard deviation, with range or percentage in some parameters

Table 2 Postoperative complications

\begin{tabular}{lccl}
\hline & Group I, $\mathbf{N = 2 0}$ & Group II, $\mathbf{N}=\mathbf{2 0}$ & $\boldsymbol{P}$-value \\
\hline No complications & $19(95.0 \%)$ & $18(90.0 \%)$ & 0.81 \\
Mild complications & $1(5.0 \%)$ & $2(10.0 \%)$ & 0.085 \\
\hline
\end{tabular}

Table 3 Surgical outcome

\begin{tabular}{lccl}
\hline & Group I, $\mathbf{N}=\mathbf{2 0}$ & Group II, $\mathbf{N = 2 0}$ & $\boldsymbol{P}$-value \\
\hline Successful closure & $16(80.0 \%)$ & $14(70.0 \%)$ & 0.81 \\
Recurrent fistula & $4(20.0 \%)$ & $6(30.0 \%)$ & 0.085 \\
\hline
\end{tabular}

and in group II, it was $3.15 \mathrm{~mm} \pm 0.75$. Fistulae were either coronal, distal, or mid in the penile shaft. There was no statistically significant difference between both groups as shown in Table 1.

No statistically significant difference was seen regarding postoperative complications between both groups with $P$-value of 0.89 . Two cases showed early complications in group II representing $10 \%$ of the group population in the form of one case had a postoperative infection, and broad-spectrum oral and topical antibiotics were prescribed until the infection subsided and the other case showed penile edema and bruising that was resolved on an anti-edematous drug was prescribed. On the other hand, group I showed a single case of early postoperative complications representing $5 \%$ of the group population in the form of penile edema that was managed conservatively. No cases had an allergic reaction to isoamyl 2-cyanoacrylate as shown in Table 2.

After 6 months of the operation, the results of the techniques were evaluated. In group I, the success rate was $80 \%(16 / 20)$, while in group II the success rate was $70 \%(14 / 20)$. The difference was not statistically significant $(P$-value $=0.465)$ as shown in Table 3 . Table 4 demonstrates the surgical technique that was used in each group.
Table 4 Surgical technique used to repair hypospadias

\begin{tabular}{lcc}
\hline Surgical technique & Group I, $\mathbf{N = \mathbf { 2 0 }}$ & $\begin{array}{l}\text { Group II, } \\
\mathbf{N}=\mathbf{2 0}\end{array}$ \\
\hline Duckett & 1 & 0 \\
Onlay & 1 & 1 \\
Snodgrass & 8 & 7 \\
Mathieu & 10 & 12 \\
Total & 20 & 20 \\
\hline
\end{tabular}

MAGPI meatal advancement and glanuloplasty technique

\section{Discussion}

Despite the various modifications employed by surgeons in hypospadias surgical repair to achieve successful urethral closure, UCF remains one of the most bothersome postoperative complications [13]. UCF incidence was $0.5 \%$ to $10 \%$ for the meatal advancement and glanuloplasty technique and up to $5-11 \%$ for tubularization procedures, while it reached up to $15-35 \%$ for free grafttubed repair [6, 14-16].

UCF usually occurs in the weak points of the reconstructed urethral tube due to several etiologies as an inadequate cicatrization process, distal stenotic segment of the urethra or due to infective processes especially with the insufficient blood supply to the repaired areas $[17,18]$.

Some small fistulas can close spontaneously in the first few months following surgical repair [12]. However, the majority of cases require another surgical intervention. Various surgical techniques may be used in the attempt of UCF repair including multilayer simple closure technique, rotational dartos or skin flaps, and advancement flaps which may be used to enhance fistula closure. Nonetheless, the risk of UCF recurrence still represents a challenge for surgeons despite multilayered closures [17, 18].

For this reason, further modifications have been suggested to improve the success of UCF repairs. Among the new modifications is the use of fibrin glue and cyanoacrylate. In a study by Gopal et al., fibrin glue has been used as a sealant material in hypospadias surgery but did not 
eliminate fistula formation. However, it minimized its incidence $[18,19]$.

Isoamyl 2-cyanoacrylate is an advanced tissue adhesive that is gamma sterilized and the properties of being nonpigmented, non-toxic, non-allergic, and biostatic. It has been used in improving wound closure with less scarring with a reduced risk of postoperative surgical site infection. In addition, it is simple to use and it shows adequate safety. There are no reports of any carcinogenic effects of cyanoacrylate. Cyanoacrylates have been widely used in various procedures since the Cochrane database report in 2004, which stated that tissue glue should be used by surgeons as an alternative to the suturing material as it has been shown to be effective for wound healing with less infection and leakage [20-22].

The use of cyanoacrylate has been primarily reported for skin closure after post-hypospadias fistula repair. Tan et al. reported their experience with the use of octyl cyanoacrylate in 37 children undergoing hypospadias surgery for skin closure after placing a few sutures to align the skin edges. UCF recurrence was found in only four patients $(11 \%)$ with a success rate of about $(89 \%)$ [23].

Cyanoacrylate glue was later used with a successful outcome in UCF closure without surgical intervention [24]. Lapointe et al. reported their experience in the repair of UCF using cyanoacrylate glue with a $63 \%$ success rate (5/8 patients) [25]. Prestipino et al. also used cyanoacrylate glue for the closure of UCF after hypospadias repair in 13 cases: six children with early UCF (less than $72 \mathrm{~h}$ after urinary catheter removal following hypospadias repair) and seven children with late presenting UCF (up to 6 months after hypospadias repair). Successful fistula closure was achieved in seven cases (54\%) [12].

In a randomized clinical trial by González et al. that included 42 children with UCF following surgical repair of hypospadias, 21 children underwent fistula closure by using cyanoacrylate glue as an outpatient procedure and 21 were treated surgically. Of the UCFs treated with cyanoacrylate, $60 \%$ were closed entirely compared to $68 \%$ of the surgical group [13].

In our study, we are presenting a novel technique by adding cyanoacrylate glue during the surgical repair beneath the dartos layer coverage of the repaired fistula. This technique is an attempt to improve fistula closure and eliminate recurrence by forming a tight adhesive bacteriostatic layer over the sutured urethra beneath the dartos flap. Despite fewer cases of the recurrent fistula with the cyanoacrylate group ( $4 / 20$ cases) versus $(6 / 20$ cases) in the control group, adding cyanoacrylate did not statistically improve the success rate of fistula closure.

Regarding the postoperative complications, there were reports that demonstrated antibacterial properties for the cyanoacrylate glue [26]. Cyanoacrylate glue has a bacteriostatic effect against gram-positive rather than gramnegative bacteria [27]. In the present study, none of the cases of group I showed wound infection in postoperative follow-up; however, one case of group II had wound infection. Hosseini et al. reported the beneficial effects in decreasing the incidence of hematomas and infections in patients treated with adhesive glue [28]. We had a similar incidence of mild bruising in both groups. Overall, there was no statistically significant difference between groups as regards the occurrence of mild complications in the postoperative period, with a complication rate of $5 \%$ and $10 \%$ in group I and II, respectively.

The limitations of this study included the relatively small number of patients to obtain a statistically significant result. However, cyanoacrylate remains promising and evaluating this agent on a larger group of patients is recommended to evaluate its efficacy.

\section{Conclusion}

The application of cyanoacrylate during UCF repair was feasible and safe. The successful repair of UCF was found to be higher with cyanoacrylate. However, we could not demonstrate a statistically significant difference between the two groups. Therefore, future studies with a larger sample size to explore the benefit of cyanoacrylate are warranted.

\section{Abbreviations}

UCF: urethro-cutaneous fistula.

\section{Acknowledgements}

Not applicable.

\section{Authors' contributions}

AMT was involved in study design, primary surgeon, and discussion writing, AMM was involved in study design and methodology and collected the data. $\mathrm{AH}$ (corresponding author) was involved in results and discussion writing. AF was involved in manuscript writing and final revision. KOE was involved in final revision and abstract writing. AT was the primary surgeon and collected the data. AR was involved in study design and final revision. All authors have read and approved the final version of the manuscript.

Funding

We received no fund in our study.

\section{Availability of data and materials}

The datasets used and/or analyzed during the current study are available from the corresponding author on reasonable request.

\section{Declarations}

Ethical approval and consent for participation Full written informed consent was obtained from all patients' guardians before their inclusion in the study. The protocol was approved by the Research Ethics Committee of Faculty of Medicine; Ain Shams University (approval no. FMASU MS 75/2018). The study was performed in accordance with the ethical standards as laid down in the 1964 Declaration of Helsinki and its later amendments. 


\section{Consent for publication}

Not applicable.

\section{Competing interests}

The authors declare that they have no conflict of interest.

Received: 24 October 2020 Accepted: 22 June 2021

Published online: 05 July 2021

\section{References}

1. Springer A, van den Heijkant M, Baumann S. Worldwide prevalence of hypospadias. J Pediatr Urol [Internet]. 2016;12(3):152.e1-152.e7. Available from: http://dx.doi.org/https://doi.org/10.1016/j.jpurol.2015.12.002

2. Sheng X, Xu D, Wu Y, Yu Y, Chen J, Qi J (2018) The risk factors of Urethrocutaneous fistula after hypospadias surgery in the youth population. BMC Urol 18(1):1-6

3. Shukla AR, Patel RP, Canning DA (2004) Hypospadias. Urol Clin North Am [Internet] 31(3):445-460

4. Barbagli G, Perovic S, Djinovic R, Sansalone S, Lazzeri M (2010) Retrospective descriptive analysis of 1176 patients with failed hypospadias repair. J Urol [Internet] 183(1):207-211. https://doi.org/10.1016/j.juro.2009.08.153

5. Muruganandham K, Ansari MS, Dubey D, Mandhani A, Srivastava A, Kapoor R et al (2010) Urethrocutaneous fistula after hypospadias repair: Outcome of three types of closure techniques. Pediatr Surg Int 26(3):305-308

6. Roberts J (2010) Hypospadias surgery past, present and future. Curr Opin Urol [Internet]. 20(6):483-489

7. Elbakry A (2001) Management of urethrocutaneous fistula after hypospadias repair: 10 Years' experience. BJU Int 88(6):590-595

8. Agrawal K, Misra A (2013) Unfavourable results in hypospadias. Indian J Plast Surg [Internet]. 46(2):419

9. Springer A (2014) Assessment of outcome in hypospadias surgery - a review. Front Pediatr [Internet]. https://doi.org/10.3389/fped.2014.00002/ abstract

10. Elwakil R, Montasser MF, Abdelhakam SM, Ibrahim WA (2015) N-butyl2-cyanoacrylate, iso-amyl-2-cyanoacrylate and hypertonic glucose with $72 \%$ chromated glycerin in gastric varices. World J Gastrointest Endosc 7(4):411

11. Mattick A, Clegg G, Beattie T, Ahmad T (2002) A randomised, controlled trial comparing a tissue adhesive (2-octylcyanoacrylate) with adhesive strips (Steristrips) for paediatric laceration repair. Emerg Med J 19(5):405-407

12. Prestipino M, Bertozzi M, Nardi N, Appignani A (2011) Outpatient department repair of urethrocutaneous fistulae using n-butyl-cyanoacrylate (NBCA): A single-centre experience. BJU Int 108(9):1514-1517

13. Ambriz-González G, Aguirre-Ramirez P, García-De León JM, León-Frutos FJ, Montero-Cruz SA, Trujillo X et al (2014) 2-octyl cyanoacrylate versus reintervention for closure of urethrocutaneous fistulae after urethroplasty for hypospadias: A randomized controlled trial. BMC Urol 14(1):2-7

14. Al-kandari AM, Elzayat T, Shokeir AA (2008) A long-term results of 764 patients.

15. Devine CJ, Horton CE (1977) Hypospadias repair. J Urol [Internet] 118(1(II)):188-193. https://doi.org/10.1016/S0022-5347(17)57943-4

16. Akbiyik F, Tiryaki T, Senel E, Mambet E, Llvanelloglu Z, Atayurt H, (2009) Clinical experience in hypospadias: results of tubularized incised plate in 496 patients. Urology 73(6):1255-1257

17. Shankar KR, Losty PD, Hopper M, Wong L, Rickwood AMK (2002) Outcome of hypospadias fistula repair. BJU Int 89(1):103-105

18. Ambriz-González G, Aguirre-Ramirez P, García-de León JM, León-Frutos FJ, Montero-Cruz SA, Trujillo X et al (2014) 2-octyl cyanoacrylate versus reintervention for closure of urethrocutaneous fistulae after urethroplasty for hypospadias: a randomized controlled trial. BMC Urol [Internet] 14(1):93. https://doi.org/10.1186/1471-2490-14-93

19. Gopal SC, Gangopadhyay AN, Mohan TV, Upadhyaya VD, Pandey A, Upad hyaya A et al (2008) Use of fibrin glue in preventing urethrocutaneous fistula after hypospadias repair. J Pediatr Surg 43(10):1869-1872

20. Devrukhkar V, Hegde R, Khare S, Saraf T (2015) Evaluation of isoamyl 2-cyanoacrylate tissue adhesive in management of pediatric lacerations: an alternative to suturing. Ann Maxillofac Surg 5(1):49

21. Coulthard $P$, Worthington $H$, Esposito $M$, van der Elst, van Waes OJF Tissue adhesives for closure of surgical incisions. J Tissue Viability. 4(2):67

22. Nagpal BM, Kumar G, Nagi GS, Singh P (2004) Sutureless closure of operative skin wounds. Med J Armed Forces India 60(2):131-133

23. Tan HL, Nah SA, Budianto II, Sehat S, Tamba R (2012) The use of octyl cyanoacrylate (superglue) in hypospadias repair including its use as a fixator for urethral stents. J Pediatr Surg [Internet] 47(12):2294-2297. https://doi.org/10.1016/j.jpedsurg.2012.09.022

24. Bardari F, D'Urso L, Muto G (2001) Conservative treatment of iatrogenic urinary fistulas: the value of cyanoacrylic glue. Urology 58(6):1046-1048

25. Lapointe SP, N-Fékété C, Lortat-Jacob S (2002) Early closure of fistula after hypospadias surgery using $\mathrm{N}$-butyl cyanoacrylate: preliminary results. J Urol [Internet]. 168(4):1751-1753

26. Eiferman RA, Snyder JW (1983) Antibacterial effect of cyanoacrylate glue. Arch Ophthalmol 101(6):958-960

27. Romero IL, Malta JBNS, Silva CB, Mimica LMJ, Soong KH, Hida RY (2009) Antibacterial properties of cyanoacrylate tissue adhesive: Does the polymerization reaction play a role. Indian J Ophthalmol 57(5):341-344

28. Hosseini SMV, Rasekhi AR, Zarenezhad M, Hedjazi A (2012) Cyanoacrylate glue dressing for hypospadias surgery. N Am J Med Sci 4(7):320-322

\section{Publisher's Note}

Springer Nature remains neutral with regard to jurisdictional claims in published maps and institutional affiliations.

\section{Submit your manuscript to a SpringerOpen ${ }^{\circ}$ journal and benefit from:}

- Convenient online submission

- Rigorous peer review

- Open access: articles freely available online

- High visibility within the field

Retaining the copyright to your article

Submit your next manuscript at springeropen.com 